\title{
Experimental Neuronal Injury in the Newborn Lamb: A Comparison of $N$-Methyl-D-Aspartic Acid Receptor Blockade and Nitric Oxide Synthesis Inhibition on Lesion Size and Cerebral Hyperemia
}

\author{
GEORGE A. TAYLOR, WILLIAM H. TRESCHER, MICHAEL V. JOHNSTON, AND \\ RICHARD J. TRAYSTMAN
}

The Russell H. Morgan Department of Radiology [G.A.T.], Department of Pediatrics [G.A.T., M.V.J.], Department of Neurology [M.H.T., M.V.J.], Department of Anesthesiology and Critical Care Medicine [R.J.T.], The Johns Hopkins Medical Institutions, and from The Kennedy-Kreiger Institute [W.H.T.],

Baltimore, Maryland

\section{ABSTRACT}

The purpose of this study was to compare the effects of dizocilipine maleate (MK-801) and $N^{G}$-nitro-L-arginine methyl ester (L-NAME) on focal excitotoxic brain injury and associated hemodynamic response in the newborn lamb. A 27 gauge needle was placed into the right striatum in 28 anesthetized newborn lambs. Seven animals were placed in each group. A negative control group received $0.2 \mathrm{~mL}$ of buffered saline, a positive control group received $5 \mu \mathrm{mol}$ of $N$-methyl-D-aspartic acid (NMDA) alone, and two groups received NMDA and pretreatment with L-NAME. Ultrasound images and cerebral blood flow determinations (microspheres) were obtained before, and at 20 , 40 , and $60 \mathrm{~min}$ after, intrastrial injection. Three animals in each group underwent histopathologic evaluation. Sonographic lesions were visible immediately after intracerebral injection. Saline injection resulted in small lesions (mean volume; $13.6 \pm 5$ $\mathrm{mm}^{3}$ ) without hyperemia. NMDA alone resulted in larger lesions $\left(92.9 \pm 24 \mathrm{~mm}^{3}\right)$ and hyperemia to both hemispheres, whereas pretreatment with MK-801 reduced lesion size $\left(11.7 \pm 6 \mathrm{~mm}^{3}\right)$ and completely ablated cerebral hyperemia. Pretreatment with
L-NAME showed no effect on lesion size $\left(69.9 \pm 20 \mathrm{~mm}^{3}\right)$ and hyperemia only in the ipsilateral hemisphere. Sonographic lesions correlated well with gross and histopathologic appearance. We concluded that NMDA-induced focal brain injury and associated hyperemia in the newborn lamb appear to be specific NMDA receptor-mediated events. NO production probably does not play a major part in NMDA-induced neonatal neuronal injury, and may be only partly responsible for regional hyperemia during NMDA injection. (Pediatr Res 38: 644-651, 1995)
Abbreviations
NMDA, $N$-methyl-D-aspartic acid
L-NAME, $N^{\mathrm{G}}$-nitro-L-arginine methyl ester
MK-801, dizocilipine maleate
NO, nitric oxide
CVR, cerebrovascular resistance
CBF, cerebral blood flow
ANOVA, analysis of variance

There is considerable evidence now suggesting that glutamate may mediate the neurotoxicity observed in hypoxicischemic brain injury. Several sources of data support this hypothesis: (i) glutamate produces neuronal injury similar to that observed after cerebral hypoxia-ischemia; (ii) elevated extracellular levels of glutamate and aspartate are present during cerebral ischemia; (iii) excitatory deafferentation results in improved neuronal survival; and (iv) NMDA receptor an-

Received January 5, 1995; accepted May 9, 1995.

Correspondence: George A. Taylor, M.D., Department of Radiology, Children's Hospital, 300 Longwood Avenue, Boston, MA 02115.

Supported in part by U.S. Public Health Service, National Institutes of Health Grant NS 20020, and by The Society for Pediatric Radiology. tagonists exhibit neuroprotective effects under a variety of experimental conditions (1-4). Although NMDA antagonists may be of therapeutic value in several forms of acute brain injury, the pharmacology of these compounds is complex, and their effects on the developing animal are not always predictable. For example, MK-801 is a powerful NMDA receptor antagonist with high efficacy in preventing hypoxic-ischemic brain injury in the infant rat model (5). However, under certain circumstances, acute administration of MK-801 to postnatal d 7 rats results in up-regulation of the number of NMDA receptors and a paradoxical enhancement of the NMDA-mediated brain injury as MK-801 levels diminish in the brain (6). A number of factors may influence the extent of brain injury after 
ischemia, including changes in CBF. There is now evidence that NO participates in regulation of the cerebral circulation (7). However, the role of NO during cerebral ischemia is poorly understood. Acute administration of $\mathrm{NO}$ inhibitors have been reported to be either protective $(7,8)$ or deleterious $(7,9)$ during focal cerebral ischemia. Little information is available regarding the hemodynamic effects of NMDA and NO synthase antagonists in the neonatal animal, and whether the protective effects of these agents are in part due to alterations in regional hemodynamics.

In the current study, we compare the effects of a noncompetitive NMDA receptor antagonist, MK-801, and a NO synthase inhibitor (L-NAME) on focal excitotoxic brain injury and the associated hemodynamic response in the newborn lamb model. Our hypothesis is that focal lesions and hemodynamic disturbances associated with intrastrial injection of NMDA are receptor-mediated and modulated by NO.

We chose the neonatal lamb as our model for the following reasons. 1) The size and developmental features of neonatal lamb brain more closely approximate those of the full-term infant compared with the neonatal rodent brain. Regional blood flow studies and sonographic characterization of excitotoxic lesions would not be possible in smaller rodent species. 2) Fetal and neonatal lamb brain has been extensively used as a model for the study of hypoxic-ischemic brain injury (10-13). 3) NO synthase is expressed in high levels throughout the 1-7-d-old newborn lamb brain (14-15).

\section{METHODS}

Twenty-eight mixed breed newborn lambs (mean age $4.2 \mathrm{~d}$, range 1-7 d) were anesthetized with i.v. pentobarbital (12-15 $\mathrm{mg} / \mathrm{kg}$ loading dose; $3 \mathrm{mg} / \mathrm{kg} / \mathrm{h}$ continuous drip), intubated, and mechanically ventilated using a Harvard pump respirator (Harvard Apparatus, Dover, MA). Core body (rectal) temperature was monitored and maintained between 37 and $38^{\circ} \mathrm{C}$ in every animal. The eye blink reflex, pedal reflex, and withdrawal from pain were used to document adequate anesthesia. Polyvinyl catheters (Martech Medical Products, Harlysville, PA) were placed in the right femoral artery for continuous blood pressure monitoring, and right femoral vein for administration of i.v. fluids and medications in every animal. In lambs in which CBF determinations were obtained, additional catheters were placed in the left ventricle (via the right brachiocephalic artery) for injection of radiolabeled microspheres, the left axillary artery for obtaining microsphere reference samples, and sagittal sinus for obtaining mixed cerebral venous blood gases. A $1 \times 5-\mathrm{cm}$ transverse bone flap was removed across the midline, approximately $1.5 \mathrm{~cm}$ anterior to the lambda. This bony window was used for sonographic access and for placement of a sagittal sinus catheter.

The animals were divided into one control group and three experimental groups each containing seven animals. In every lamb, a 27 gauge needle was placed into the right striatum, using a stereotactic device, and under direct sonographic visualization. Control animals received $0.2 \mathrm{~mL}$ of $0.1 \mathrm{M}$ PBS (pH 7.4) to assess the individual effects of intracerebral injection alone. All other animals received $5 \mu \mathrm{mol}$ of NMDA in $0.2 \mathrm{~mL}$ of buffered saline. Each intracerebral injection was performed over $2 \mathrm{~min}$, and the needle was left in place for an additional 2 min before removal. The first experimental group received the intracerebral injection of NMDA without pretreatment. The two remaining experimental groups were pretreated with either a noncompetitive NMDA receptor antagonist (MK-801, $5 \mathrm{mg}$ / $\mathrm{kg})$, or L-NAME $(60 \mathrm{mg} / \mathrm{kg})$, a NO synthase inhibitor, each given $60 \mathrm{~min}$ before intracerebral injection of NMDA. These doses were determined by review of pertinent experimental literature (16-18).

Sonographic guidance for needle placement was performed using a high resolution computerized ultrasound unit (ACUSON 128 XP, Mountainview, CA), equipped with a vector 7.0 $\mathrm{MHz}$ transducer. Serial images were obtained in coronal projection before and after intracerebral injection using a $7.0 \mathrm{MHz}$ linear transducer. The image was magnified so that it filled the entire screen. Imaging parameters were set to maximize the dynamic range of the image. Frame averaging was set at a persistence setting of 4 , a moderate edge-enhancing function was selected (preprocessing setting 1 ), and the log compression was set at $53 \mathrm{~dB}$. The greatest dimension of each lesion was measured in the $x, y$, and $z$ axis on sonographic images, and the volume estimated by the formula for volume of an ellipsoid ( $[X$ $\times Y \times Z] / 2$ ).

CBF determinations were obtained in four of seven lambs from each group using the radiolabeled microsphere technique (19). We used six different microspheres measuring $16 \pm 0.5$ $\mu \mathrm{m}$ in diameter, each labeled with one of the following isotopes, ${ }^{114} \mathrm{In},{ }^{113} \mathrm{Sn},{ }^{103} \mathrm{Ru},{ }^{95} \mathrm{Nb},{ }^{46} \mathrm{Sc}$, and ${ }^{153} \mathrm{Gd}$, and suspended in a solution containing approximately $1.4 \times 10^{6}$ microspheres in each vial (Dupont, Boston, MA). The microspheres were chosen in random order, and $0.4 \mathrm{~mL}$ was injected over $45 \mathrm{~s}$ into the left ventricular catheter. A reference blood sample was simultaneously withdrawn from the axillary artery at a rate of $2.5 \mathrm{~mL} / \mathrm{min}$ over $1 \mathrm{~min}$ with a calibrated syringe (Harvard Apparatus, Dover, MA). Withdrawal rates were confirmed by weighing the syringe before and after obtaining the reference sample and by timing the withdrawal interval with an electronic timer. Tissue and reference blood samples were counted in a deep well gamma counter (Packard Instruments, Downers Groves, IL). Right and left diencephalon, midbrain, caudate nucleus, and cerebellum were separated from other structures and submitted for radioactivity measurements as whole structures. Regional CBF (mL/min/100 g of brain tissue) was determined for each of the above structures, as well as for total brain and each cerebral hemisphere. A weighted average of individual radioactivity measurements (expressed per $100 \mathrm{~g}$ of tissue) was used to derive regional CBF for total brain and cerebral hemispheres. Regional CVR $(\mathrm{mm} \mathrm{Hg} / \mathrm{mL} / \mathrm{min} / 100 \mathrm{~g}$ ) was determined for total brain and right and left hemispheres.

Estimates of cerebral metabolism. Cerebral hemispheric oxygen extraction was calculated using the formula $\left(\mathrm{CaO}_{2}-\right.$ $\mathrm{CvO}_{2}$ )/CaO ${ }_{2}$, where $\mathrm{CaO}_{2}$ is arterial oxygen content, and $\mathrm{CvO}_{2}$ is mixed cerebral venous oxygen content. Oxygen content was calculated by the formula: $\left(\mathrm{Po}_{2} \times 0.003\right)+(\mathrm{Hb}[\mathrm{g}] \times 1.34 \times$ $\% \mathrm{O}_{2}$ saturation). Cerebral hemispheric oxygen consumption ( $\mathrm{mL}$ of $\mathrm{O}_{2} / \mathrm{mL} / \mathrm{min} / 100 \mathrm{~g}$ ) was calculated by the formula CBF 
$\left(\mathrm{CaO}_{2}-\mathrm{CvO}_{2}\right)$, where $\mathrm{CBF}$ is blood flow to the cerebral hemispheres in $\mathrm{mL} / \mathrm{min} / 100 \mathrm{~g}$ of brain.

Mean arterial blood pressure and pulse pressure were continuously monitored using a multichannel recorder (Gould Instruments, Ormand $\mathrm{CA}$ ). Arterial and mixed venous (sagittal sinus) $\mathrm{pH}, \mathrm{PCO}_{2}$, and $\mathrm{Po}_{2}$ were measured at $39.5^{\circ} \mathrm{C}$ using a Radiometer ABL 30 (Radiometer, Cleveland, $\mathrm{OH}$ ), Oxygen saturation and $\mathrm{Hb}$ were measured using the Hemoximeter OSM2 (Radiometer) calibrated for lamb's blood.

CBF determinations, blood pressure, and arterial and sagittal sinus blood gases were obtained at baseline, after a 30-min equilibration period after surgery, $60 \mathrm{~min}$ after i.v. injection of MK-801, or L-NAME, and at 20,40 , and 60 min after intracerebral injection of buffered saline, or NMDA.

The animals were killed $70-80$ min after NMDA injection with an i.v. overdose of pentobarbital and saturated potassium chloride.

Experimental, anesthesia, and euthanasia protocols were approved by The Johns Hopkins University Institutional Animal Care and Use Committee, and are consistent with the recommendations of the American Veterinary Medical Association.

Catheter placement was verified at autopsy, and the brain was removed for microsphere analysis $(n=16)$. CBF determinations were not performed in 12 animals (three from each group). In these animals, the brain was removed and preserved in $10 \%$ formalin for $10-14 \mathrm{~d}$. Each specimen was then sectioned in standard coronal projection, and the location and size of the lesion was correlated with the appearance on sonography. Histologic sections were obtained through the basal ganglia and stained with hematoxylin and eosin.

Data analysis. The sonographic features for each lesion studied were described and correlated with gross and histologic appearance on pathologic examination. Animals receiving NMDA antagonists or L-NAME were compared with those animals not receiving pretreatment with respect to changes in histologic characteristics, and average size of NMDA-induced lesions.

Both absolute and relative changes in regional CBF (expressed as \% change from baseline) were used for analysis. Differences in CBF, cerebrovascular resistance, and other physiologic variables at each interval were analyzed using a two-way repeated measures ANOVA. Comparisons of CBF among treatment groups at each interval, as well as lesion size among treatment groups were performed using a factorial ANOVA. All values are expressed as \pm SEM.

\section{RESULTS}

Sonographic lesions consisted of well defined areas of increased echogenicity and ranged in volume from $<0.7$ to 203 $\mathrm{mm}^{3}$. When present, focal lesions could be identified on real time sonography, within 30-60 s after intracerebral injection, and did not change in size thereafter until the end of the experiment.

In the negative control (buffered saline), intracerebral lesions were detected in $71 \%$ of animals, with a mean lesion size of $13.6 \pm 5 \mathrm{~mm}^{3}$. In the positive control (untreated NMDA) group, lesions were observed in every animal, and mean lesion size $\left(92.9 \pm 24 \mathrm{~mm}^{3}\right)$ was larger than in saline-injected animals $(p<0.007)$. Pretreatment with MK-801 reduced the frequency $(57 \%)$ and mean size $\left(11.7 \pm 6 \mathrm{~mm}^{3}\right)$ of NMDAinduced lesions ( $p<0.05$ for both comparisons), whereas pretreatment with L-NAME resulted in no effect on either lesion frequency $(93 \%)$ or size $\left(69.9 \pm 20 \mathrm{~mm}^{3}, p=0.46\right)$ compared with untreated NMDA injection (Fig. 1).

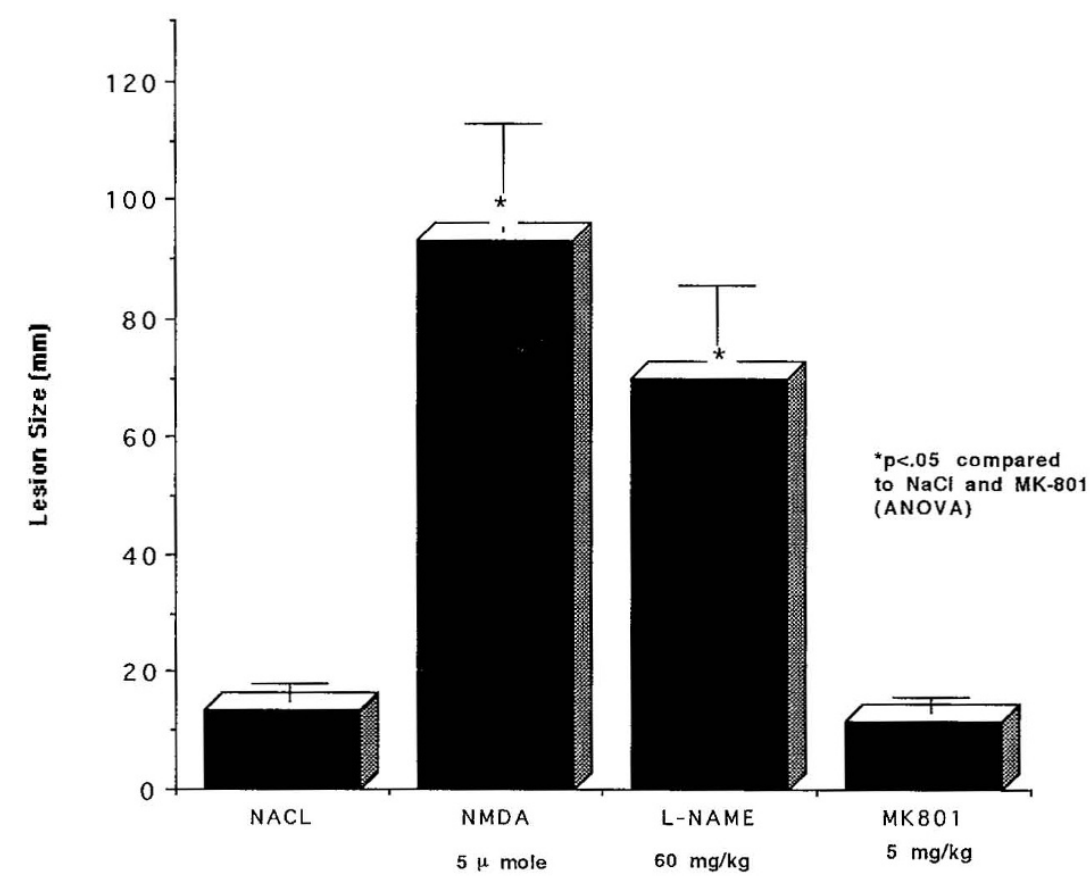

Figure 1. Lesion size $\left(\mathrm{mm}^{3}\right)$ in animals receiving intrastriatal NMDA alone, buffered saline alone (NACL), and in animals receiving NMDA after pretreatment with MK-801 or L-NAME. 
Size and contour of focal brain lesions noted on ultrasound correlated well with gross pathologic findings (Fig. 2). Histologically, the NMDA lesions were characterized by focal areas of petechial hemorrhage, with shrinkage and triangulation of the nucleus and cytoplasm, and microvacuolization consistent with early neuronal injury (Fig. 3). There were no histologic differences in type of injury among the animals receiving pretreatment with MK-801 or L-NAME. Only small hemorrhagic foci were detected in the three animals injected with buffered saline (Fig. 4).

Figure 5 shows changes in regional $\mathrm{CBF}$ before and after intracerebral injection of buffered saline or NMDA, respectively.

Intracerebral injection of buffered saline (negative control) was not associated with any significant regional or global hyperemia after injection. Supratentorial CBF was $61 \pm 8,66$ $\pm 14,47 \pm 7$, and $58 \pm 7 \mathrm{~mL} / \mathrm{min} / 100 \mathrm{~g}$ before, and 20,40 , and 60 min after saline injection $(p>0.5)$. Hemispheric CVR also remained unchanged, ranging between $1.2 \pm 0.1$ and 1.8 $\pm 0.2 \mathrm{~mm} \mathrm{Hg} / \mathrm{mL} / \mathrm{min} / 100 \mathrm{~g}$ before and after saline injection.

Injection of NMDA (positive control), however, resulted in regional and global hyperemia involving both hemispheres. The most marked elevation in CBF was seen in ipsilateral midbrain ( $p=0.0006$ by ANOVA). Increased CBF was
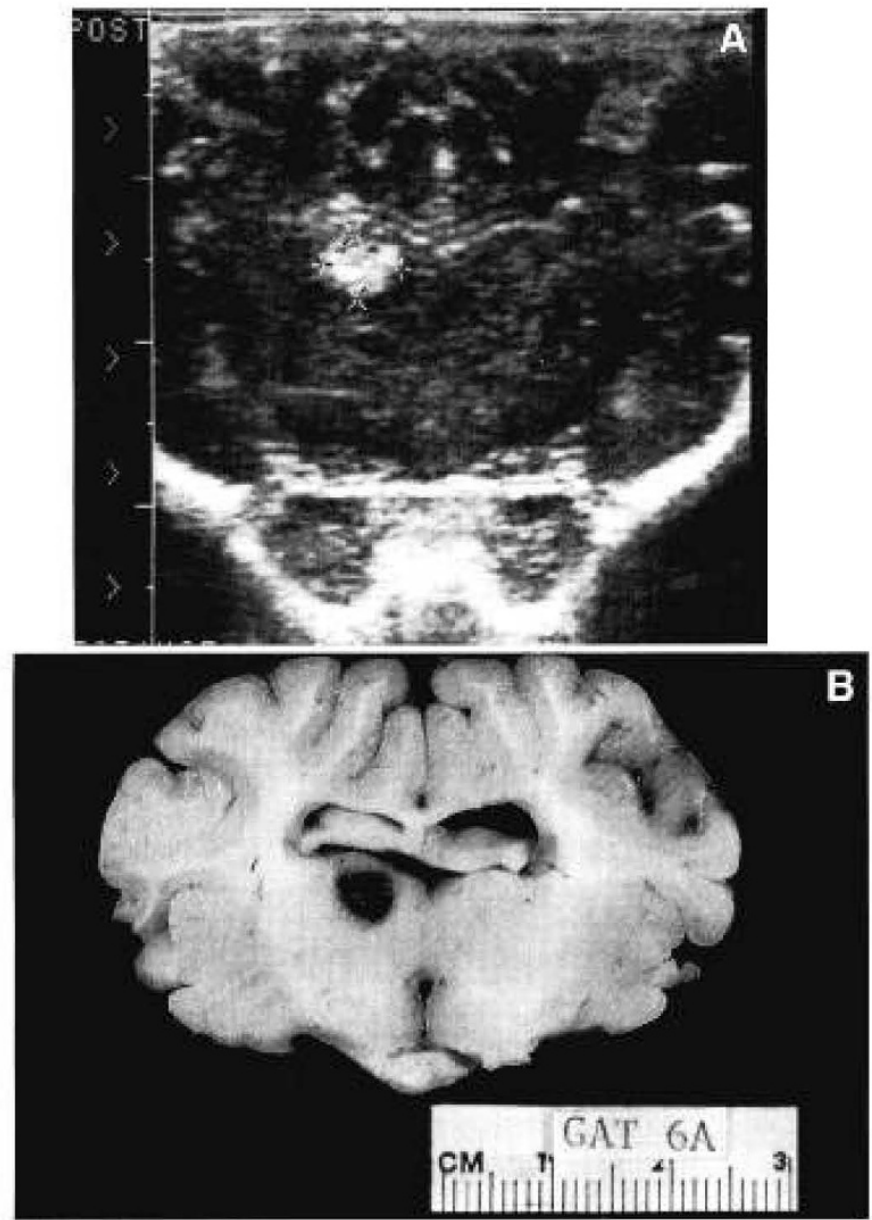

Figure 2. Sonographic and gross pathologic findings in NMDA lesion. $(A)$ Cranial sonogram in coronal orientation obtained $20 \mathrm{~min}$ after NMDA injection shows well-defined echogenic lesion in right striatum. $(B)$ Gross brain specimen confirms location and size of sonographic lesion.

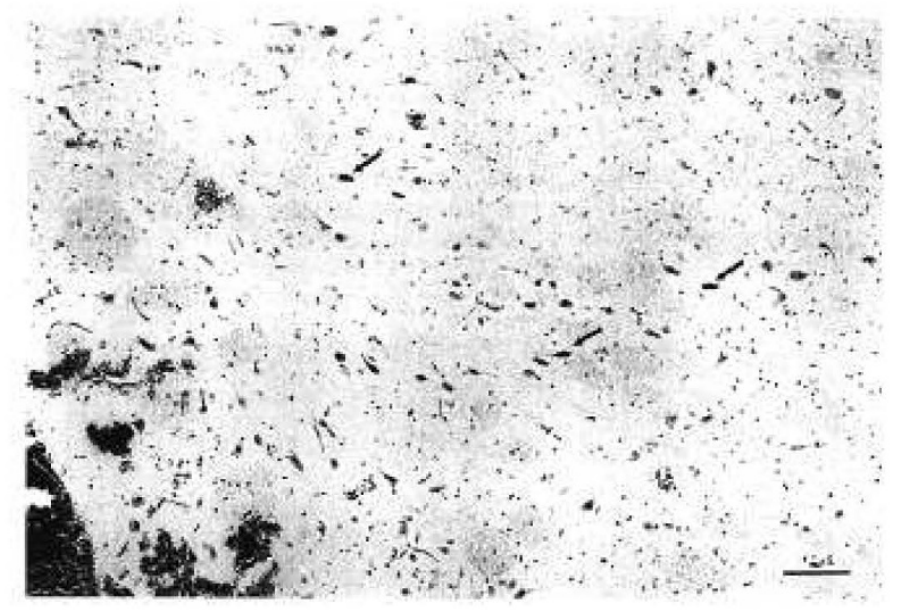

Figure 3. Histologic findings-NMDA. Striatum after injection of $5 \mu \mathrm{mol}$ of NMDA shows focal areas of hemorrhage and shrinkage and triangulation of neuronal nuclei consistent with early neuronal injury (arrows). Hematoxylin and eosin stain, bar $=100 \mu \mathrm{m}$.

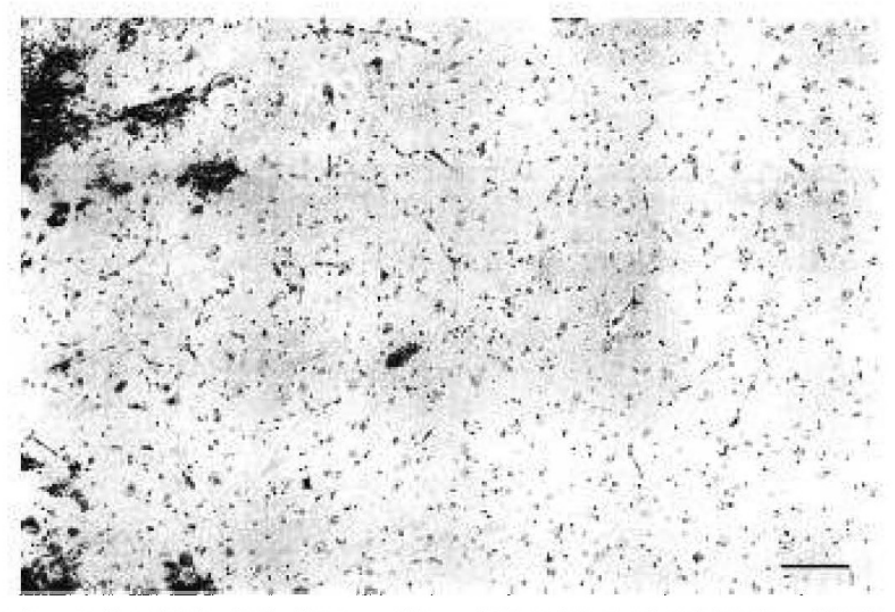

Figure 4. Histologic findings-saline. Right striatum after injection of buffered saline shows focal areas of petechial hemorrhage. No neuronal abnormalities are evident. Hematoxylin and eosin stain, bar $=100 \mu \mathrm{m}$.

widespread and symmetric throughout both hemispheres, cerebellum, medulla, and pons. Similarly, supratentorial CVR decreased from $1.2 \pm 0.1$ to $0.53 \pm 0.1 \mathrm{Hg} / \mathrm{mL} / \mathrm{min} / 100 \mathrm{~g}$ after injection $(p=0.0001)$. There was no difference in percent change in CBF between both hemispheres at any interval after NMDA injection ( $p>0.27$ by 2-tailed paired $t$ test).

Although a transient increase in mean blood pressure was seen during L-NAME administration, neither MK-801 or LNAME had an effect on supratentorial blood flow $60 \mathrm{~min}$ after the pretreatment dose and before intracerebral NMDA injection $(p<0.1$ by ANOVA).

Pretreatment with MK-801 resulted in near complete ablation of the hyperemic response to NMDA injection. Mean CBF to the midbrain, diencephalon, cerebellum, pons, medulla, and cerebral hemispheres, and supratentorial CVR were unchanged after NMDA injection $(p>0.5)$. Animals pretreated with L-NAME showed an asymmetric hemodynamic response to NMDA injection. CBF in areas closest to the injection site (ipsilateral midbrain and diencephalon) increased $(p<0.04)$ and was indistinguishable from that observed in untreated NMDA injection $(p>0.25)$. In the ipsilateral cerebral hemisphere, hyperemia was present, but less than found in untreated 

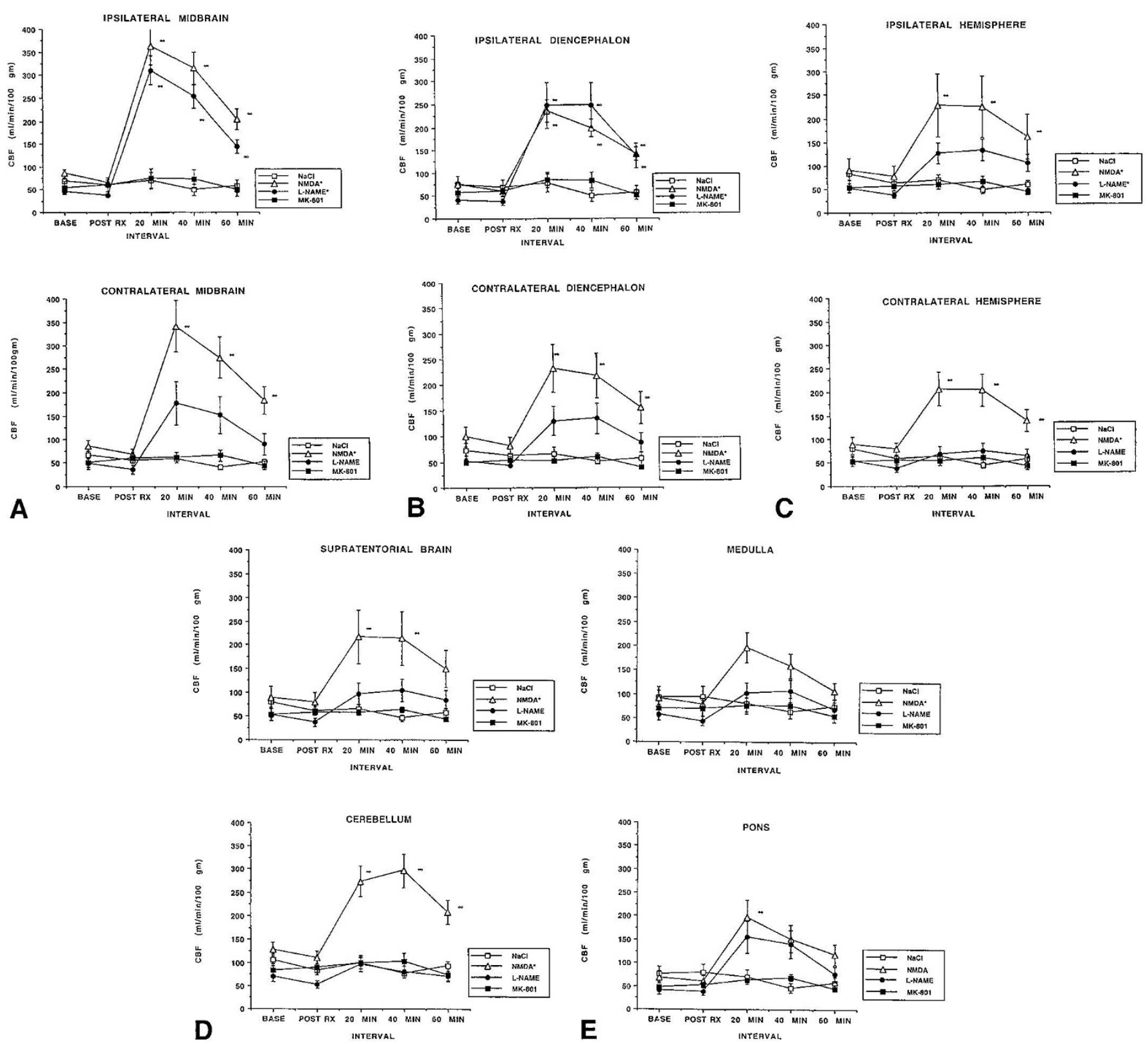

Figure 5. $(A-E)$ Regional CBF determinations by treatment group at baseline, after pretreatment, and at 20, 40, and 60 min after intrastriatal NMDA injection. $*=p<0.05$ by ANOVA compared with $\mathrm{NaCl} . \infty=p<05$ by ANOVA compared with baseline values.

NMDA injection $(p<0.0001)$. This was associated with a drop in CVR to ipsilateral hemisphere, from $1.5-2.4 \mathrm{Hg} / \mathrm{mL} /$ $\mathrm{min} / 100$ preinjection, to $0.8-1.0 \mathrm{Hg} / \mathrm{mL} / \mathrm{min} / 100$ after injection $(p<0.003)$. Hyperemic response in contralateral cerebral hemisphere, however, was completely ablated, with both $\mathrm{CBF}$ and CVR remaining unchanged. Although these animals showed a tendency toward higher supratentorial $\mathrm{CBF}$, it only approached statistical significance $(p<0.06)$.

Within each treatment category, there was no correlation between lesion size and percent change in regional or global CBF.

Physiologic measurements obtained for each experimental group are presented in Table 1. Hemispheric cerebral metabolic rate (cerebral oxygen consumption), mean arterial blood pressure, $\mathrm{Hb}, \mathrm{PCO}_{2}$, and $\mathrm{O}_{2}$ content were not affected by saline or NMDA injection with or without pretreatment. A significant metabolic acidosis was observed at 20 and 40 min after NMDA injection in animals receiving NMDA only. This was associated with a trend toward decreasing mean arterial blood pressure, suggesting a lactic acidemia due to systemic underperfusion.

\section{DISCUSSION}

In the current study, intrastrial injection of NMDA resulted in focal lesions with histologic characteristics of early infarction and generalized cerebral hyperemia. These data confirm our previous findings on the histologic and hemodynamic effects of intrastrial NMDA injection (20). The new findings of this study are that pretreatment with MK- 801 attenuated both 
Table 1. Physiologic variables following NMDA injection into right striatum

\begin{tabular}{|c|c|c|c|c|c|c|c|}
\hline \multirow[b]{2}{*}{ Variable } & \multicolumn{3}{|c|}{ Interval } & \multicolumn{3}{|c|}{ Minutes after NMDA } & \multirow[b]{2}{*}{$p$} \\
\hline & Treatment & Baseline & Posttreatment & 20 & 40 & 60 & \\
\hline \multirow[t]{4}{*}{$\mathrm{BP}(\mathrm{mm} \mathrm{Hg})$} & $\mathrm{NaCl}$ & $96 \pm 4$ & $88 \pm 5$ & $81 \pm 5$ & $83 \pm 4$ & $81 \pm 6$ & 0.16 \\
\hline & NMDA & $99 \pm 9$ & $95 \pm 9$ & $107 \pm 10$ & $98 \pm 6$ & $88 \pm 6$ & 0.59 \\
\hline & MK-801 & $97 \pm 5$ & $111 \pm 15$ & $86 \pm 4$ & $88 \pm 5$ & $82 \pm 3$ & 0.11 \\
\hline & L-NAME & $77 \pm 5$ & $86 \pm 6$ & $99 \pm 10$ & $95 \pm 5$ & $86 \pm 3$ & 0.17 \\
\hline \multirow[t]{4}{*}{$\mathrm{pH}$} & $\mathrm{NaCl}$ & $7.38 \pm 0.02$ & $7.37 \pm 0.03$ & $7.35 \pm 0.03$ & $7.33 \pm 0.02$ & $7.36 \pm 0.03$ & 0.64 \\
\hline & NMDA & $7.37 \pm 0.04$ & $7.35 \pm 0.04$ & $7.23 \pm 0.05$ & $7.15 \pm 0.04$ & $7.13 \pm 0.06$ & 0.01 \\
\hline & MK-801 & $7.36 \pm 0.02$ & $7.34 \pm 0.03$ & $7.28 \pm 0.03$ & $7.30 \pm 0.01$ & $7.31 \pm 0.01$ & 0.15 \\
\hline & L-NAME & $7.34 \pm 0.02$ & $7.31 \pm 0.05$ & $7.28 \pm 0.04$ & $7.23 \pm 0.05$ & $7.22 \pm 0.05$ & 0.27 \\
\hline \multirow[t]{4}{*}{$\mathrm{Hb}(\mathrm{g})$} & $\mathrm{NaCl}$ & $9.8 \pm 0.4$ & $9.2 \pm 0.3$ & $9.6 \pm 0.2$ & $9.7 \pm 0.2$ & $9.8 \pm 0.3$ & 0.52 \\
\hline & NMDA & $9.2 \pm 0.6$ & $9.0 \pm 0.6$ & $10.6 \pm 0.8$ & $9.8 \pm 0.8$ & $10.9 \pm 0.9$ & 0.33 \\
\hline & MK-801 & $10.7 \pm 0.7$ & $10.8 \pm 0.7$ & $11.9 \pm 1$ & $12.1 \pm 1$ & $12.3 \pm 1$ & 0.63 \\
\hline & L-NAME & $9.0 \pm 0.7$ & $9.9 \pm 0.7$ & $9.9 \pm 1$ & $28.2 \pm 2$ & $10.5 \pm 0.8$ & 0.34 \\
\hline \multirow[t]{4}{*}{$\mathrm{A}-\mathrm{O}_{2}$ content $(\mathrm{mL} / \mathrm{g} \mathrm{Hb})$} & $\mathrm{NaCl}$ & $12.9 \pm 0.2$ & $11.8 \pm 0.2$ & $12.2 \pm 0.3$ & $12.6 \pm 0.2$ & $12.8 \pm 0.3$ & 0.03 \\
\hline & NMDA & $11.8 \pm 0.9$ & $11.9 \pm 0.9$ & $13.2 \pm 0.8$ & $12.4 \pm 0.9$ & $13.5 \pm 0.9$ & 0.55 \\
\hline & MK-801 & $14.0 \pm 0.9$ & $14.1 \pm 0.8$ & $14.6 \pm 1$ & $15.4 \pm 1$ & $15.3 \pm 1$ & 0.85 \\
\hline & L-NAME & $11.8 \pm 0.1$ & $12.6 \pm 1$ & $13.0 \pm 1$ & $14.0 \pm 1$ & $13.9 \pm 1$ & 0.62 \\
\hline \multirow[t]{4}{*}{$\mathrm{PCO}_{2}(\mathrm{kPa})$} & $\mathrm{NaCl}$ & $265 \pm 8$ & $257 \pm 8$ & $281 \pm 7$ & $280 \pm 8$ & $248 \pm 15$ & 0.08 \\
\hline & NMDA & $263 \pm 23$ & $254 \pm 15$ & $285 \pm 8$ & $274 \pm 5$ & $261 \pm 23$ & 0.58 \\
\hline & MK-801 & $270 \pm 15$ & $263 \pm 23$ & $272 \pm 23$ & $272 \pm 2$ & $276 \pm 8$ & 0.98 \\
\hline & L-NAME & $280 \pm 8$ & $285 \pm 15$ & $266 \pm 15$ & $291 \pm 8$ & $274 \pm 15$ & 0.72 \\
\hline \multirow{4}{*}{$\mathrm{CMRO}_{2}\left(\mathrm{~mL} \mathrm{O}_{2} / \mathrm{mL} / \mathrm{min} / 100 \mathrm{~g}\right)$} & $\mathrm{NaCl}$ & $3.6 \pm 0.6$ & $2.5 \pm 0.3$ & $2.9 \pm 0.7$ & $2.2 \pm 0.4$ & $3.1 \pm 0.6$ & 0.38 \\
\hline & NMDA & $4.1 \pm 0.7$ & $3.7 \pm 0.4$ & $3.0 \pm 0.1$ & $3.2 \pm 0.3$ & $3.3 \pm 0.6$ & 0.58 \\
\hline & MK-801 & $2.3 \pm 0.2$ & $2.1 \pm 0.1$ & $2.1 \pm 0.3$ & $2.4 \pm 0.2$ & $1.9 \pm 0.3$ & 0.5 \\
\hline & L-NAME & $2.7 \pm 0.4$ & $2.7 \pm 0.3$ & $4.2 \pm 1$ & $5.4 \pm 0.8$ & $3.9 \pm 0.4$ & 0.07 \\
\hline
\end{tabular}

Physiologic variables at baseline and before and after intrastriatal injection were compared by ANOVA. Baseline: initial measurements before pretreatment with MK-801 or L-NAME. Posttreatment: measurements obtained after pretreatment with MK-801 or L-NAME, and before intrastriatal injection. This measure represents a second baseline measure in animals not receiving pretreatment. BP, mean arterial blood pressure; $\mathrm{pH}$, arterial $\mathrm{pH}$; $\mathrm{Hb}$, arterial hemoglobin; $\mathrm{A}-\mathrm{O}_{2}$, arterial oxygen content; $\mathrm{PCO}_{2}$, arterial partial pressure $\mathrm{CO}_{2}$ (kilopascals); $\mathrm{CMRO}_{2}$, cerebral oxygen consumption.

lesion frequency and volume, and completely ablated the hyperemic cerebrovascular response, whereas L-NAME appeared to have no neuroprotective effects, and only ablated cerebral hyperemia in the hemisphere contralateral to the NMDA injection site.

The efficacy of MK- 801 as a neuroprotective agent has been well documented in both ischemic, and in NMDA-induced models of brain injury using adult animals $(3,16,21,22)$. Its effects on the cerebral vasculature, however, appear to be quite variable and dependent on species and experimental model used. In normal dogs, for example, MK-801 increases CBF, but appears to have no hemodynamic effect when given after an episode of complete cerebral ischemia (23). Conversely, in the rat model, it reduces regional $\mathrm{CBF}$ in the cerebral hemisphere contralateral to middle cerebral artery occlusion (24). In rabbits, MK-801 attenuates postischemic hypoperfusion in the penumbral region of brain after middle cerebral artery occlusion (25). In addition, cerebrovascular effects of MK-801 may be modified by anesthesia. MK-801 increases hemispheric $\mathrm{CBF}$ in conscious rats, but results in no change or a decrease in $\mathrm{CBF}$ in the $\alpha$-chloralose-anesthetized rat (26). In the current study, using pentobarbital-anesthetized lambs, pretreatment with MK-801 appeared to completely block cerebral hyperemia induced by intrastrial NMDA injection. These data strongly suggest that both the neuronal injury and associated hyperemic response in this model are NMDA receptormediated phenomena.
There are three potential mechanisms by which NMDA receptor antagonists may inhibit vasodilatation: by a direct effect on cerebral resistance vessels, by increasing cerebral oxidative metabolism, and by altering production of a second vasodilatory substance.

A direct effect on the cerebral vasculature is unlikely, because NMDA receptor complexes have not been demonstrated in sheep microvessels (27). It is possible that, in the current study, a small amount of NMDA may have leaked along the needle tract to the surface of the brain. However, it is unlikely that arterioles deep within the contralateral hemisphere, or in infratentorial structures, were exposed directly to injected NMDA.

A second mechanism by which MK-801 may exert its hemodynamic effect is by inhibiting the release of a second vasodilatory substance such as NO. NO is known to exert potent vasodilatory effects on the cerebral circulation $(11,12$, $22,23)$. NMDA receptor activation has been associated with an increase in intracellular NO levels in rat brain slices $(28,29)$ and in the somatosensory cortex during peripheral nerve stimulation. These changes can be uncoupled by the introduction of an inhibitor of NO synthase (30). Using microdialisis techniques, Northington and Traystman (31) have shown that the elevation of regional CBF and NO production associated with intracerebral perfusion with NMDA is ablated by adding LNAME, a potent NO synthase enzyme inhibitor. 
During focal cerebral ischemia, a sharp, transient increase in NO occurs with subsequent activation of guanylate cyclase (32). However, it is not clear whether NO enhances or serves as a protective influence on glutamate-mediated neurotoxicity (8). Although Demerle-Pallardy et al. (9) showed no change in neuronal injury produced by L-glutamate or hypoxia when brain cells were treated with L-NAME, Nowicki et al. (28) showed that inhibition of NO production resulted in a dramatic $72 \%$ reduction in infarct volume. Similarly, Dawson et al. (33) showed mediation of glutaminergic neurotoxicity by $\mathrm{NO}$ via NMDA receptors in cerebral cortical cultures. These disparate results may be due to the nonselective blockade of endothelial, neuronal, and inducible NO synthase by L-NAME. In a study using mice deficient in neuronal NO synthase, Huang et al. (34) have shown a reduction in infarct size after middle cerebral artery occlusion in mice deficient in neuronal NO synthase compared with wild-type mice. When these mutant mice were treated with L-NAME to inhibit endothelial NO synthase, infarct size increased to baseline levels (34). In the current study, pretreatment with L-NAME resulted in no neuroprotective effect and a strikingly asymmetric CBF response. Although there was no reduction in hyperemia in the ipsilateral hemisphere, there was complete ablation of this response in the contralateral side. The dose of L-NAME used in this study (60 $\mathrm{mg} / \mathrm{kg}$, i.v.) is within the range demonstrated to result in $>90 \%$ inhibition of NO synthase for 1-30 h after administration (32). It is possible that direct intrastrial injection of NMDA resulted in incomplete inhibition of NO synthase in areas of brain closer to the injection site and a differential effect on the cerebral vasculature.

A third potential mechanism is inhibition of neuronal overstimulation by NMDA and accompanying vasodilatation (35, 36). This may be due in part to intra- and extracellular acidosis associated with neuronal injury and the likely disruption of oxidative metabolism produced by NMDA overstimulation. There are abundant fiber interconnections throughout the basal ganglia that form part of complex reciprocating circuits with the cerebral cortex and thalamus. Overstimulation of neurons in the basal ganglia (striatum) by injected NMDA may result in excitation and subsequent vasodilatation in other remote regions receiving afferent input from these areas. Postsynaptic NMDA receptors exist on catecholaminergic neurons containing NO synthase. Thus, NO produced by these cells may act as a spatial signal to facilitate the release of neurotransmitters from surrounding synapses $(37,38)$. Therefore, either inhibition of neuronal overstimulation by MK-801 or inhibition of neuronal NO synthase by L-NAME would result in at least partial attenuation of hyperemia. This explanation would be consistent with our findings of asymmetric suppression of cerebral hyperemia by L-NAME only in the contralateral hemisphere.

Although the exact mechanisms by which NMDA induces cerebral hyperemia remain unclear, the results of this study strongly suggest that these effects are NMDA receptormediated phenomena and that NO production may not play a major part in NMDA-induced neuronal injury in the newborn animal. The consistent strong neuroprotective effects of MK801 despite its widely variable hemodynamic effects on various experimental animal models make it unlikely that the neuroprotective and hemodynamic effects of this compound are related (24). The findings in this study should be extrapolated to ischemic conditions cautiously, because the vascular effects of MK-801 may be different in ischemic and nonischemic tissues.

\section{REFERENCES}

1. Massieu L, Thedinga KH, McVey M, Fagg GE 1993 A comparative analysis of the neuroprotective properties of competitive and uncompetitive $\mathrm{N}$-methyl-D-aspartate receptor antagonists in vivo: implications for the process of excitotoxic degeneration and its therapy. Neuroscience 55:883-892

2. Klesh KW, Murphy TF, Scher MS, Buchanan DE, Maxwell EP, Cook TM, Crutcher A 1986 Intrahippocampal injection of kainic acid produces significant pyramidal cell loss in neonatal rats. Neuroscience 18:79-92

3. McDonald JW, Silverstein FS, Johnston MV 1987 MK-801 protects the neonatal brain from hypoxic ischemic damage Eur J Pharmacol 140:359-361

4. Young RSK, Petroff OAC, Aquila WJ, Yates J 1991 Effects of glutamate, quisqualate, and $N$-methyl-D-aspartate in neonatal brain. Exp Neurol 111:362-368

5. McDonald JW, Silverstein FS, Johnston MV 1988 Neurotoxicity of $N$-methyl-Daspartate is markedly enhanced in developing rat central nervous system. Brain Res 459:200-203

6. McDonald JW, Johnston MV 1990 Physiological and pathophysiological roles of excitatory amino acids during central nervous system development. Brain Res Rev 15:41-70

7. Faraci FM, Brian JE 1993 Nitric oxide and the cerebral circulation. Stroke 25:692703

8. Dalkara T. Moskowitz MA 1994 The complex role of nitric oxide in the pathophysiology of focal cerebral ischemia. [review] Brain Pathol 4:49-57

9. Demerle-Pallardy C, Lonchampt M-O, Chabrier P-E, Braquet P 1991 Absence of implication of L-arginine/nitric oxide pathway on neuronal cell injury induced by L-glutamate or hypoxia. Biochem Biophys Res Commun 181:456-464

10. Short BL, Bender K, Walker LK, Traystman RJ 1994 The Cerebrovascular response to prolonged hypoxia with carotid artery and jugular vein ligation in the newborn lamb. J Pediatr Surg 29:887-891

11. Tweed A, Cote J, Lou H, Gregory G, Wade J 1986 Impairment of cerebral blood flow autoregulation in the newborn lamb by hypoxia. Pediatr Res 20:516-519

12. Younkin DP, Wagerle LE, Chance B, Maria J, Delivoria-Papadopoulos M 1987 ${ }^{31} \mathrm{P}-\mathrm{NMR}$ studies of cerebral metabolic changes during graded hypoxia in newborn lambs. J Appl Physiol 62:1569-1574

13. Tan WK, Williams CE, Gunn AJ, Malland CE, Gluckman PD 1992 Suppression of postischemic epileptiform activity with MK-801 improves neural outcome in fetal sheep. Ann Neurol 32:677-682

14. Northington FJ, Tobin JR, Koehler RC, Traystman RJ 1994 Ontogeny of nitric oxide synthase (NOS) activity from mid-gestation to adulthood. Pediatr Res 35:389A (abstr)

15. Northington FJ, Koehler RC, Traystman RJ, Martin LJ 1994 Brain and endothelial nitric oxide synthase expression is regionally and temporally regulated in fetal sheep brain. Soc Neurosci Abstr 20:1301

16. McCulloch J, Ozyurt E, Kun Park C, Nehls DG, Teasdale GM, Graham DI 1993 Glutamate receptor antagonists in experimental focal cerebral ischaemia. Acta Neurochir Suppl 57:73-79

17. Palmer RMJ, Ferrige AG, Moncada S 1987 Nitric Oxide release accounts for the biological activity of endothelium-derived relaxing factor. Nature 327:524-526

18. Ignarro LJ, Buga GM, Wood KS, Byrns RE, Chaudhuri G 1987 Endothelium-derived relaxing factor produced and released from artery and vein is nitric oxide. Proc Natl Acad Sci USA 84:9265-9269

19. Heymann MA, Payne BD, Hoffman JIE, Rudolph AM 1977 Blood flow measurements with radionuclide-labeled particles. Prog Cardiovasc Dis 20:55-77

20. Taylor GA, Trescher WH, Traystman RJ, Johnston MV 1993 Acute experimental neuronal injury in the newborn lamb: US characterization and demonstration of hemodynamic effects. Pediatr Radiol 23:268-275

21. Ikonomidou C, MosingerJL, Shahid Sales K, Labruyere J, Olney JW 1989 Sensitivity of the developing rat brain to hypobaric/ischemic damage parallels sensitivity to $\mathrm{N}$-methyl-D-aspartate neurotoxicity. J Neurosci 9:2809-2818

22. Buchan AM, Slivka A, Xue D 1992 The effect of the NMDA receptor antagonist MK-801 on cerebral blood flow and infarct volume in experimental focal stroke. Brain Res 574:171-177

23. Perkins WJ, Lanier WL, Karlsson BR, Milde JH, Michenfelder JD 1989 The effect of the excitatory amino acid receptor antagonist dizocilipine maleate (MK-801) on hemispheric cerebral blood flow and metabolism in dogs: modification by prior complete cerebral ischemia. Brain Res 498:34-44

24. Park CK, Nehls DG, Teasdale GM, McCulloch J 1989 Effect of the NMDA antagonist MK-801 on local cerebral blood flow in focal cerebral ischaemia in the rat. J Cerebr Blood Flow Metab 9:617-622

25. Meyer FB, Anderson RE, Friedrich PF 1990 MK-801 attenuates capillary bed compression and hypoperfusion following incomplete focal cerebral ischemia. J Cereb Blood Flow Metab 10:895-902

26. Roussel S, Pinard E, Seylaz J 1992 The acute effects of MK-801 on cerebral blood flow and tissue partial pressures of oxygen and carbon dioxide in conscious and alpha-chloralose anaesthetized rats. Neuroscience 47:959-965 
27. Beart PM, Sheehan K-A M, Manallack DT 1988 Absence of $N$-methyl-Daspartate receptors on ovine cerebral microvessels. J Cereb Blood Flow Metab 8:879-882

28. Nowicki JP, Duval D, Poignet H, Scatton B 1991 Nitric oxide mediates neuronal death after focal cerebral ischemia in the mouse. Eur J Pharmacol 204:339-340

29. Snyder SH, Bredt DS 1991 Nitric oxide as a neuronal messenger. Trends Pharmacol Sci $12: 125-128$

30. Northington FN, Matherene GP, Berne RM 1992 Competitive inhibition of nitric oxide synthase prevents the cortical hyperemia associated with peripheral nerve stimulation. Proc Natl Acad Sci USA 89:6649-6652

31. Northington FJ, Traystman RJ 1993 Local infusion of $N$-methyl-D-aspartate (NMDA) produces increases in cerebral blood flow (CBF) that can be blocked by the nitric oxide (NO) synthase antagonist $N$-nitro-L-arginine methyl ester (L-NAME). Pediatr Res 33:227A(abstr)

32. Kader A, Frazzini VI, Solomon RA, Trifiletti RR 1993 Nitric oxide production during focal cerebral ischemia in rats. Stroke 24:1709-1716

33. Dawson VL, Dawson TM, London ED, Bredt DS, Snyder SH 1991 Nitric oxide mediates glutamate neurotoxicity in primary cortical culture. Proc Natl Acad Sci USA $88: 6368-6371$

34. Huang Z, Huang PL, Panahian N, Dalkara T, Fishman MC, Moskowitz MA 1994 Effects of cerebral ischemia in mice deficient in neuronal nitric oxide synthase. Science 265:1883-1885

35. Arneric SP, Honig MA, Milner TA, Greco S, Iadecola C, Reis DJ 1988 Neuronal and endothelial sites of acetylcholine synthesis and release associated with microvessels in rat cerebral cortex: ultrastructural and neurochemical studies. Brain Res 454:11-30

36. Garthwaite J 1991 Glutamate, nitric oxide and cell-cell signaling in the nervous system. Trends Neurosci 14:60

37. Edvinsson L, Mackenzie ET, McCullough J, Uddman R 1987 Perivascular innervation and receptor mechanisms in cerebrovascular bed. In: Wood JH (ed) Cerebral Blood Flow: Physiologic and Clinical Aspects. McGraw-Hill, New York, pp 145-172

38. Edelman GM, Gally JA 1992 Nitric oxide: linking space and time in the brain. Proc Natl Acad Sci USA 89:11651-11652 